\title{
NOVOS DANOS DA RESPONSABILIDADE CIVIL NO DIREITO BRASILEIRO
}

\author{
NEW FORMS OF DAMAGES IN BRAZILIAN CIVIL LIABILITY LAW
}

Recebido em 07/02/2018

Aprovado em 05/05/2018

\section{MARIA FERNANDA CÉSAR LAS CASAS DE OLIVEIRA1 RENATA MARIA SILVEIRA TOLEDO²}

RESUMO: O presente artigo apresenta as novas modalidades de danos que surgem de alguns julgados brasileiros, sua necessidade e possibilidade jurídica. Para tanto, faz o estudo de danos no contexto da dignidade da pessoa humana, como vêm sendo examinadas algumas dessas modalidades e como se caracterizam. Com isto, analisamos a real existência de novos danos ou se estes são apenas designações do mesmo dano moral.

PALAVRAS-CHAVES: Responsabilidade Civil, Novos Danos Morais, Dignidade da Pessoa Humana

ABSTRACT: This article presents the new forms of damages that arise from some Brazilian judges, their necessity and legal possibility. Therefore, it does the study of damages in the context of the dignity of the human person, as some of these modalities have been examined and how they are characterized. With this, we analyze the real existence of new damages or if these are only designations of the same moral damage.

KEYWORDS: Civil Liability, New Moral Damages, Dignity of the Human Person

\footnotetext{
1 Mestranda em Direito pela FADISP e assistente docente na mesma instituição. Bolsista pela CAPES/CNPq pelo Programa de Pós-Graduação Stricto Sensu em Direito da Faculdade Autônoma de Direito - FADISP, em conformidade com a Portaria CAPES n ${ }^{\circ} 181 / 2012$, professora da pós-graduação em Civil e Processo Civil no Pró-Ordem unidade Santo André e da pós-graduação em Família e Sucessões e Processo Civil na ESA/SCS , pós-graduada em Direito de Família e Sucessões pela ESA/SP, assistente editorial na Revista Pensamento Jurídico - QUALIS B1, membro das Comissões de Direito de Família e Sucessões e da Mulher Advogada, ambas da OAB/SP, da Comissão de Direito do Consumidor da OAB/Santos, membro do Instituto Brasileiro de Direito de Família (IBDFAM) e da International Society of Family Law. Palestrante da OAB/SP. Advogada.

2 Mestranda em Direito pela FADISP e Assistente Docente na mesma Instituição. Pós-graduada em Processo Civil Brasileiro pela PUC-SP e em Direitos Difusos e Coletivos pela Escola Superior do Ministério Público de São Paulo. Advogada
} 


\section{INTRODUÇÃO}

A Constituição Federal de 1988, ao eleger como fundamento da República o princípio da dignidade da pessoa humana, colocou-a no centro de preocupação do Direito, ao mesmo tempo em que estabeleceu uma cláusula geral de tutela da pessoa humana. Por esta razão, o dano moral pode ser compreendido como lesão a um ou a vários atributos da personalidade que ofendem a dignidade da pessoa humana. Entretanto, não há um rol definido de interesses que, violados, signifiquem dano moral. Mesmo assim, em seu artigo $5^{\circ}$, V, a Constituição Federal determina a reparação integral do dano e faz menção expressa a dano moral, material e à imagem. Deve-se lembrar que as funções da reparação civil são compensatórias, punitivas e persecutórias.

Diante dessas premissas, admitir novas espécies autônomas de danos morais é corolário lógico. Nota-se, igualmente, a tendência dos julgados em reconhecer a existência de novas hipóteses. Assim, danos por abandono afetivo, estético, por quebra à busca pela felicidade, por perda da chance, coletivo, social, entre outros, surgem em clara tendência para garantir reparação integral.

\section{O PRINCÍPIO DA DIGNIDADE DA PESSOA HUMANA E OS DIREITOS DA PERSONALIDADE}

O termo “dignidade humana” passou a ser utilizado a partir da Declaração Universal dos Direitos Humanos, em 1948, cujo preâmbulo afirma ser esta um dos fundamentos da "liberdade, da justiça e da paz no mundo"3.

No Brasil, o princípio da dignidade da pessoa humana é valor fundamental da Constituição Federal de 1988, previsto no artigo 1º, III. Para Schreiber, “a dignidade humana é o valor-síntese que reúne as esferas essenciais do desenvolvimento e realização da pessoa humana"4.

\footnotetext{
3 Disponível em: <www.onu.org.br/img/2014/09/DUDH.pdf>. Acesso em: 14 jun. 2017.
}

4 SCHREIBER, Anderson. Direitos da personalidade. 3.ed. São Paulo:Atlas, 2014. p. 8. 
Apesar de possuir caráter aberto, esse princípio constitucional tem seu conteúdo preenchido pelos direitos da personalidade5, os quais "são aqueles inerentes à pessoa e à sua dignidade"6, assim definidos por Tartuce. Venosa7 esclarece que "a personalidade não é exatamente um direito; é um conceito básico sobre o qual se apoiam os direitos”. Para o autor, relaciona-se com o direito natural e constitui o conteúdo mínimo da condição humana, de caráter extrapatrimonial, cuja violação enseja um dano moral.

A IV Jornada de Direito Civil de 2006, em seu enunciado 274 do CJF/STJ, estabelece que "os direitos da personalidade regulados de maneira não exaustiva pelo CC 2002, são expressões da cláusula geral de tutela da pessoa humana prevista no artigo $1^{\circ}$, III, da Constituição Federal"'.

Assim, podemos observar que os direitos da personalidade, enquanto proteção aos atributos da pessoa humana, são regulados de maneira exemplificativa pelo Código Civil Brasileiro e preenchem o conteúdo do princípio da dignidade da pessoa humana,cuja violação enseja reparação civil.

\section{O DANO MORAL NO BRASIL}

Pressuposto da responsabilidade civil, entende-se dano como a lesão a bens ou a interesses juridicamente protegidos, como interesse econômico ou "meramente ideal ou afetivo"9, a pessoas ou a coisas, patrimonial ou extrapatrimonial, devendo ser, em qualquer caso, certo e atual. Conforme ressalta Miragem10, não é possível afirmar categoricamente que um dano a pessoa é extrapatrimonial e um dano a coisa é patrimonial; pode ocorrer do dano a pessoas ser patrimonial e do dano a coisas ser extrapatrimonial ${ }^{11}$.

\footnotetext{
5 Ibid.p. 9.

6 TARTUCE, Flávio. Direito civil 1: Lei de Introdução e parte geral. São Paulo: Método, 2015.p. 147.

7 VENOSA, Sílvio de Salvo. Direito civil: parte geral. São Paulo: Atlas, 2008. p.167-169.

8 TARTUCE, Flávio.Op cit,.p. 147.

${ }^{9}$ MIRAGEM, Bruno. Direito civil:responsabilidade civil. São Paulo: Saraiva, 2015. p 155-156.

10 Ibid.

11 Ibid p. 158-159.
} 
No Brasil, existe o sistema atípico de danos, na medida em que não se enumeram os interesses cuja violação importa dano ${ }^{12}$, mormente por ser adotada uma cláusula geral de tutela e promoção da pessoa humana ${ }^{13}$, ficando a cargo da jurisprudência definir o interesse cuja violação pode vir a ocasionar um dano.

Schreiber esclarece que o dano moral, entendido como lesão a um atributo da personalidade "se concentra sobre o objeto atingido (o interesse lesado), e não sobre as consequências emocionais, subjetivas e eventuais da lesão"14. Por corolário, desnecessária a prova do resultado danoso para a responsabilidade civil por dano moral.

\section{NOVAS ESPÉCIES DE DANOS OU NOVAS DENOMINAÇÕES DO MESMO DANO MORAL?}

Deve-se questionar se esses "novos danos" são realmente novas espécies ou várias denominações do mesmo dano moral. A definição é relevante na medida em que, se considerarmos tratar-se de um único dano moral com várias denominações, o ajuizamento de uma ação de indenização não prescinde da formulação de vários pedidos para cada hipótese de dano. De outro modo, ao coexistirem várias espécies de danos cumuláveis, para uma ação judicial de reparação de danos deve-se formular um pedido para cada hipótese fática.

Importante destacar que a Constituição Federal de 1988, em seu artigo $5^{\circ}$, V, determina a reparação integral do dano e faz menção expressa ao dano moral, material e à imagem. Posteriormente, o Superior Tribunal de Justiça, na Súmula 37, definiu a cumulação de danos material e moral oriunda do mesmo fato. Neste contexto, o STJ ao reconhecer a autonomia do dano estético, definiu sua cumulação com dano moral e material.

A ementa abaixo esclarece a influência do reconhecimento da autonomia dos danos na prática processual:

\footnotetext{
12 SCHREIBER, Anderson. Novos paradigmas da responsabilidade civil. São Paulo: Atlas, 2015.p. 102: "De fato em matéria de dano ressarcível, os ordenamentos modernos dividem-se em duas vertentes bem definidas: (i) ordenamentos típicos ou fechados, que indicam taxativamente os interesses cuja violação enseja um dano reparável; e (ii) ordenamentos atípicos ou abertos, que não empregam semelhante restrição".

13 TARTUCE, Flávio.Op.cit., p. 146.

14 SCHREIBER, Anderson. Direitos da personalidade. São Paulo: Atlas, 2014.p. 17.
} 


\section{AGRAVO REGIMENTAL. AGRAVO EM RECURSO ESPECIAL. INDENIZAÇÃO POR DANOS MORAIS E ESTÉTICOS. ACOLHIMENTO DO PEDIDO DE DANOS MORAIS. \\ Ementa:}

1. É lícita a cumulação de indenização de danos morais e de danos estéticos (Súmula n. 387/STJ).

2. Se a pretensão da parte é a fixação de danos morais e estéticos, a procedência de apenas um dos pedidos gera a sucumbência recíproca.

3. Honorários advocatícios fixados sobre o valor dado à causa pela parte autora e não sobre o valor da condenação, já considerada a sucumbência recíproca.

4. Agravo regimental desprovido. 15

Percebe-se, portanto, a tendência dos julgados em admitir a cumulação de indenização, decorrente da autonomia, e cumulação de danos suscetíveis das inúmeras hipóteses de violações, que podem decorrer da cláusula geral de tutela da pessoa humana, fundamentada no princípio da dignidade da pessoa humana.

Schreiber defende que "novos danos" surgem da flexibilização jurisprudencial na estrutura da responsabilidade civil, a qual reflete "a valorização de sua função compensatória e a crescente necessidade de assistir a vítima em uma realidade social marcada pela insuficiência das políticas públicas na administração e reparação dos danos"16.

Tartuce, durante a V Jornada de Direito Civil (2011) - Enunciado 456, recorda que "A expressão 'dano' no artigo 944 abrange não só os danos individuais, materiais ou imateriais, mas também os danos sociais, difusos, coletivos e individuais homogêneos, a serem reclamados pelos legitimados para propor ações coletivas"17.

No mesmo contexto, cite-se o Enunciado 274, aprovado na IV Jornada de Direito Civil (2006), promovida pelo Conselho da Justiça Federal e pelo Superior Tribunal de Justiça:

Os direitos da personalidade, regulados de maneira não exaustiva pelo Código Civil, são expressões da cláusula geral de tutela da pessoa humana, contida no artigo $1^{\circ}$, III, da Constituição (princípio da dignidade da pessoa humana). Em caso de colisão entre eles, como nenhum pode sobrelevar os demais, deve-se aplicar a técnica da ponderação ${ }^{18}$.

Resta reconhecida, portanto, a existência de novos danos reparáveis decorrentes da violação de novos direitos da personalidade

\footnotetext{
${ }^{15}$ AgRg no AREsp 72023 / BA, AGRAVO REGIMENTAL NO AGRAVO EM RECURSO ESPECIAL 2011/0255346-7, www.stj.jus.br. Acesso em 21.06.17

16 SCHREIBER, Anderson. Novos paradigmas da responsabilidade civil. São Paulo: Atlas, 2015. p. 83.

17 TARTUCE, Flávio. Direito civil: direito das obrigações e responsabilidade civil. São Paulo: Método/Forense, 2016.

18 Ibid, 458 .
} 


\section{AS NOVAS ESPÉCIES DE DANOS}

A responsabilidade civil por lesão aos atributos da personalidade, fundamentada no princípio constitucional da dignidade da pessoa humana, bem como a preocupação na valorização do efeito compensatório e a exigência de reparação integral, fazem surgir várias espécies de danos. Neste artigo, serão comentados o dano por abandono afetivo, estético, dano ao direito à busca pela felicidade, dano por perda da chance, danos coletivos e danos sociais.

\subsection{DANO POR ABANDONO AFETIVO}

Aqui, o dano refere-se o abandono afetivo perpetrado por pai/mãe contra seu filho. A hipótese colocada é se o dever jurídico do pai ou da mãe vai além, ou não, do dever de sustento da sua prole.

Porém, o valor jurídico do afeto encontra fundamento no princípio da dignidade da pessoa humana, que coloca a "pessoa" como centro de preocupação do Direito. Atentamos para a ementa de acórdão paradigmático sobre o tema:

\section{CIVIL E PROCESSUAL CIVIL. FAMÍLIA. ABANDONO AFETIVO. COMPENSAÇÃO POR DANO MORAL. POSSIBILIDADE.}

1. Inexistem restrições legais à aplicação das regras concernentes à responsabilidade civil e o consequente dever de indenizar/compensar no Direito de Família.

2. O cuidado como valor jurídico objetivo está incorporado no ordenamento jurídico brasileiro não com essa expressão, mas com locuções e termos que manifestam suas diversas desinências, como se observa do art. $227 \mathrm{da} \mathrm{CF} /$ 88.

3. Comprovar que a imposição legal de cuidar da prole foi descumprida implica em se reconhecer a ocorrência de ilicitude civil, sob a forma de omissão. Isso porque o non facere, que atinge um bem juridicamente tutelado, leia-se, o necessário dever de criação, educação e companhia - de cuidado - importa em vulneração da imposição legal, exsurgindo, daí, a possibilidade de se pleitear compensação por danos morais por abandono psicológico.

4. Apesar das inúmeras hipóteses que minimizam a possibilidade de pleno cuidado de um dos genitores em relação à sua prole, existe um núcleo mínimo de cuidados parentais que, para além do mero cumprimento da lei, garantam aos filhos, ao menos quanto à afetividade, condições para uma adequada formação psicológica e inserção social.

5. A caracterização do abandono afetivo, a existência de excludentes ou, ainda, fatores atenuantes - por demandarem revolvimento de matéria fáticanão podem ser objeto de reavaliação na estreita via do recurso especial.

6. A alteração do valor fixado a título de compensação por danos morais é possível, em recurso especial, nas hipóteses em que a quantia estipulada pelo Tribunal de origem revela-se irrisória ou exagerada. 


\section{Recurso especial parcialmente provido. 19}

Neste acórdão, o Superior Tribunal de Justiça reconheceu o dano por abandono afetivo, decorrente do não cumprimento de uma obrigação material, inerente a relação familiar que evidenciou falta de cuidado do genitor com a prole.

Tartuce afirma que 2016 foi o ano da "afetividade" no Superior Tribunal de Justiça Brasileiro, que, em algumas ocasiões, confirmou a relevância jurídica do afeto ${ }^{20}$. Entretanto, de 2012 até 2017, houve um aperfeiçoamento no conceito do dano por abandono afetivo pelo Superior Tribunal de Justiça. Em decisão de 2016, esta Corte expressamente exigiu demonstração específica de que houve efetivo abandono, concorrido diretamente para danos aos bens inerentes à personalidade humana, evitando-se, assim, “mercantilizar os sentimentos e instigar ações judiciais motivadas unicamente pelo interesse econômico-financeiro.”21

Ou seja, não se trata de "dar preço ao afeto" 22 , mas sim, de um dever normativo de conviver, nos termos dos artigos 227 da Constituição Federal23; nos artigos 1.589 e 1.634 do Código Civil e artigo 19 do Estatuto da Criança e do Adolescente. O afeto, aqui tratado, abrange o dever dos pais de conviver com seus filhos, assim como o dever dos filhos em respeitar a autoridade dos pais e deles cuidar quando forem idosos. De fato, o conceito jurídico de afeto é o de cuidado e convivência, corolários da liberdade de gerar e adotar filhos, e não o de "amar", que é uma faculdade24.

Dias ensina que "o dano afetivo decorre do sentimento de dor e de abandono deixado no filho pelo pai/mãe que se furta ao dever de conviver com ele", já que, "dentre os deveres decorrentes do poder familiar há o dever dos pais de ter os filhos em sua companhia e de dirigir-lhes a criação e educação (CC 1.634). É assegurado o direito de visitas ao genitor que

19RECURSO ESPECIAL No 1.159.242 - SP (2009/0193701-9). www.stj.jus.br. Acesso em 21.06.17.

20TARTUCE, Flávio. 2016: o ano da afetividade na jurisprudência superior brasileira. Disponível em: $<$ www.flaviotartuce.adv.br>.Acesso em: 15 jun. 2017.

${ }^{21}$ RECURSO ESPECIAL n 1.493.125/SP. Rel. Min. Ricardo Villas BôasCueva. D.J. 23/02/2016, Disponível em: https://ww2.stj.jus.br/processo/revista/inteiroteor/?num_registro=201401313524\&dt_publicacao=01/03/2016 acessado em 07.08.2017.

${ }^{22}$ HIRONAKA, Giselda Maria Fernandes de Novaes. Os contornos jurídicos da responsabilidade afetiva nas relações entre pais e filhos - além da obrigação legal de caráter material. Disponível em: http://egov.ufsc.br/ portal/sites/default/files/anexos/32839-40754-1-PB.pdf, 2005, p.31. Acesso em: 15 jun. 2017.

23Artigo 227 da Constituição Federal: "É dever da família, da sociedade e do Estado assegurar à criança, ao adolescente e ao jovem, com absoluta prioridade, o direito à vida, à saúde, à alimentação, à educação, ao lazer, à profissionalização, à cultura, à dignidade, ao respeito, à liberdade, e à convivência familiar e comunitária, além de coloca-lo a salvo de toda forma de negligência, discriminação, exploração, violência, crueldade e opressão."

24 Informativo STJ 496, REsp 1.1.59.242/SP (Apelação com revisão 5119034700), TJSP, Rel. Des. Caetano Lagrasta, j. 12.08.2008. 
não possui a guarda (CC 1.589)"25. A autora ainda esclarece que o dano que enseja indenização, pode ser tanto por abandono material quanto por abandono espiritual, moral, psicológico, decorrentes do não exercício da convivência familiar.

Ora, o genitor que não detém a guarda não tem apenas o direito de visitar o seu filho, mas, sobretudo, uma "obrigação de conviver com ele." 26 Nesse contexto a indenização busca penalizar a violação dos direitos morais contidos nos direitos fundados na formação da personalidade do filho, exercendo a indenização duplo papel: compensatório e punitivo ${ }^{27}$.

\subsection{DANO ESTÉTICO}

Nas palavras de Lopes, dano estético é

Lesão a um direito da personalidade - o direito à integridade física, especialmente física, especialmente na sua aparência externa, na imagem que se apresenta. Como todo direito da personalidade, qualquer dano que o seu titular possa sofrer vai ter consequências materiais e, principalmente, morais. Portanto, não podemos conceber prejuízo estético que não seja também prejuízo moral, pois a pessoa, a partir do momento da lesão, está menos feliz do que era antes ou, como quer Minozzi, o dano vem perturbar "ilnostrostatodi felicita"28.

Miragem sustenta que o dano estético parte do princípio de que são integrados como atributo da personalidade, tanto a saúde e a integridade física, quanto a aparência estética da pessoa. Neste entender, exige-se que haja uma lesão à integridade física (que pode ser aparente ou não) e uma perturbação anímica. $\mathrm{O}$ dano resulta dos efeitos à autoestima, e não à exposição da lesão ${ }^{29}$.

$\mathrm{Na}$ opinião de Tartuce, o dano está presente quando a pessoa sofre cicatrizes, cortes, lesão ou perda de órgãos, aleijões, amputações, entre outras anomalias. Afirma o autor ainda que o dano estético é uma terceira modalidade de dano e, conforme vem entendendo a jurisprudência, é distinto do dano moral pois há uma alteração morfológica, e pode, portanto, ser cumulado 30 .

25DIAS, Maria Berenice. Manual de direito das famílias. 7.ed.São Paulo: Revista dos Tribunais., 2010, p. 448-451.

26DIAS, Maria Berenice. Manual de direito das famílias. 7. ed. São Paulo: Revista dos Tribunais., 2010, p. 449.

${ }^{27}$ HIRONAKA, Giselda Maria Fernandes de Novaes. Op. cit., p. 32.

${ }^{28 L O P E Z, ~ T e r e s a ~ A n c o n a . ~ O ~ d a n o ~ e s t e ́ t i c o . ~ S a ̃ o ~ P a u l o: ~ R e v i s t a ~ d o s ~ T r i b u n a i s, ~ 2004 . p . ~} 64$.

29MIRAGEM, Bruno. Op.cit., p.200-201.

30TARTUCE, Flávio. Direito civil: direito das obrigações e responsabilidade civil. São Paulo: Método/Forense, 2016.p. 441. 
Importante lembrar a visão de Ancona, que defende a autonomia dos diversos tipos de danos: "danos morais diferentes e que há diversos tipos de prejuízos sofridos pela pessoa em várias dimensões, e que o mesmo evento pode dar causa a várias indenizações, cada uma a um título diferente, levando a cumulação"31.

Hoje, com a Súmula 387 não há mais essa discussão em relação ao dano estético: "É lícita a cumulação das indenizações de dano estético e moral”

\subsection{DANO POR PERDA DA CHANCE}

Por "perda da chance" entende-se a frustração de uma expectativa que, na lógica da situação concreta, poderia ocorrer.

Importante afirmar que "o dano deve ser real, atual e certo", pois o que se analisa é a chance que tem um "prognóstico do dano certo" 32 . Venosa entende que a perda da chance poderia ser considerada uma terceira modalidade de "perdas e danos", entre o dano emergente e o lucro cessante. Afirma o autor que nos casos de lucro cessante, a construção é feita sob hipótese de mais ou menos provável, sendo o juízo de probabilidade que define a perda de chance ou de oportunidade ${ }^{33}$. Vale esclarecer que o indenizável é a "chance", perdida e não o "ganho" perdido. Por essa razão, tal espécie de dano pode ser designada como "perda de oportunidade ou perda de expectativa"34.

Miragem ainda menciona dano por perda de uma chance vinda da não observância do dever de informar, que decorre da boa-fé objetiva ${ }^{35}$. Tartuce informa que a aprovação do Enunciado 444 reconhece a reparação integral dos danos por perda de uma chance e dá a exemplos de aplicação (ou não) dessa teoria ${ }^{36}$.

Assim, para melhor entendimento dessa espécie de dano, vejamos a aplicação da teoria da perda da chance:

1. Na área da advocacia, há julgados que reconhecem a aplicação desta teoria em caso

de desídia do patrono que perde prazo processual. Nos referidos julgados, percebe-se a

\footnotetext{
${ }^{31}$ LOPEZ, Teresa Ancona. Op. cit., p. 25-26.

32 VENOSA, Sílvio de Salvo. Op.cit. p. 289.

${ }^{33}$ Ibid, p. 292.

34Ibid, p. 292.

35 MIRAGEM, Bruno.Op.cit., p. 166.

36 TARTUCE, Flávio.Op.cit., p. 443-450.
} 
preocupação em provar a perda da oportunidade de vitória, devendo ser feita uma análise da real possibilidade de êxito, na hipótese de o prazo ter sido cumprido, não bastando apenas a mera alegação de descumprimento contratual ou negligência e desídia do causídico ${ }^{37}$.

2. Descumprimento contratual de congelamento de células embrionárias do cordão umbilical: afirmou-se a aplicação da teoria da perda de uma chance, sob fundamento de que o não comparecimento da empresa contratada na figura de seu representante legal, para a coleta do material no momento do parto, implicou "dano extrapatrimonial para a criança, que tem frustrada a chance de ter suas células embrionárias colhidas e armazenadas para, se for preciso, no futuro, fazer uso em tratamento de saúde" 38.

\subsection{DANO MORAL PELA QUEBRA À BUSCA PELA FELICIDADE}

Ao tratarmos sobre felicidade, a ligação do sentido da palavra com sentimento fica evidente. Esta palavra se traduz por muitos sentimentos, capazes de expressar seu significado, por exemplo: alegria, satisfação, bem-estar, prazer, júbilo, contentamento, etc. Inúmeros significados que direcionam para um conceito abstrato, indefinível e individual, mas, todos eles identificam a felicidade como algo que dá o verdadeiro propósito da vida, a realização essencial do ser.

Para Zalcman ${ }^{39}$, o direito à busca pela felicidade não consiste na ideia de um único pensador ou corrente filosófica, mas sim, o resultado do trabalho de diversos pensadores e já se encontra positivado em diversos ordenamentos jurídicos, como, por exemplo, nos Estados Unidos (1776), em sua Declaração de Independência, ou ainda, na França (1799), cujo lema

\footnotetext{
${ }^{37}$ AgInt no AREsp 893996/MG - Agravo interno no agravo em recurso especial 2016/0082531-8, STJ - Rel. Min.Assusete Magalhães, 2a Turma, DJe 14.10.2016. Apelação Cível 20160110641942APC (0017227-72.2016.8.07.0001), $7^{\mathrm{a}}$ Turma, TJDFT, Rel. Des. Leila Arlanch, 03.05.2017 (Código de Verificação: 2017 A COPARHFUOUQWAPX03C9QNZ). Apelação Cível 20120710258035 A PC (0024886-56.2012.8.07.0007) (Código de verificação: 2016ACOOF6GB646MJJKD1K9NQLH), 2 $2^{\mathrm{a}}$ Turma, TJDFT, Rel. Des.Leila Arlanch, $2^{\mathrm{a}}$ Turma, TJDFT, 08.06.2016. Apelação Cível 20110111221485APC (0033482-81.2011.8.07.0001) (Código de verificação 2015ACO3RYPMMD2GK8X1NFQ3YE2), $1^{\text {a }}$ Turma Cível, TJDFT, Rel. Des.Simone Lucindo, 11.02.2015. Apelação Cível 20120111697365APC (0046543-72.2012.8.07.0001) (Código de verificação 2014ACOV4LS3VWJQ9N3BJ32VPEZ), $1^{\text {a }}$ Turma, TJDFT, Rel. Des.Simone Lucindo, 27.08.2014.

${ }^{38}$ Recurso Especial 1.291.247/RJ (2011/0267279-8), STJ, Rel. Min. Paulo de Tarso Sanseverino, 19.08.2014, DJe01.10.2014.

39ZALCMAN, Vivian Gerstler. O direito à busca pela felicidade por intermédio da mediação na dissolução do casamento e da união estável. Monografia (Mestrado), Curso de Direito da PUC/SP, 2017, p.46.
} 
da Revolução Francesa era inspirado na busca pela felicidade (apresentava seus ideais de "liberdade, igualdade e fraternidade") e integrou o preâmbulo da Declaração dos Direitos do Homem e do Cidadão.

No entanto, Delgado ${ }^{40}$ explica que parte da doutrina nacional defende que a busca felicidade como um direito natural não inserido no ordenamento jurídico brasileiro. Por outro lado, esta mesma corrente doutrinária entende que, mesmo sem a sua inserção no direito positivo, sua simples violação já assegura à vítima a reparação por dano moral. $\mathrm{O}$ autor, contrariamente, defende que positivação já ocorreu na forma implícita, visto que o direito à busca pela felicidade é um princípio constitucional implícito.

Neste mesmo contexto, o Supremo Tribunal Federal admitiu a força normativa do princípio da busca da felicidade em julgamento do Recurso Extraordinário n ${ }^{\circ} 898.06041$. O acórdão, ao tratar sobre a paternidade socioafetiva, confirmou a existência o direito à busca pela felicidade como princípio constitucional implícito. Em outra decisão, o Tribunal Superior do Trabalho (TST) 42 concedeu indenização a um empregado da companhia telefônica "Oi", pois considerou que a jornada de trabalho excessiva configurou dano existencial.

Segundo Silva ${ }^{43}$, o dano existencial é compreendido como uma espécie de dano imaterial, sendo sua vítima o empregado: o dano é decorrente da imposição de excesso de volume de trabalho pelo empregador. Este dano está relacionado ao direito inato de todo ser humano em dispor do seu tempo livre para buscar a sua felicidade. A violação a este direito ocorre quando as imposições do empregador ao empregado geram um volume muito grande de trabalho, impedindo-o da convivência social, do descanso e de usufruir de atividades que lhe deem prazer e tragam felicidade.

Ao falarmos sobre o dano à busca da felicidade, vale lembrar os ensinamentos Sanseverino $^{44}$, que ao defender incidência da responsabilidade civil de forma autônoma,

40 DELGADO, Mario Luiz. O direito fundamental à busca da felicidade: reflexões sobre um novo dano. Disponível em: http://www.mldadv.com.br/cat-artigos/119-o-direito-fundamental-\%C3\%A0-busca-da-felicidadereflex $\% \mathrm{C} 3 \% \mathrm{~B} 5$ es-sobre-um-novo-dano.html. Acesso em: 19.12.2017

${ }^{41}$ RExt no. 898.060 com relatoria do Min. Luiz Fux, julgado em 24.08.2017, informação obtida no site: http:// stf.jus.br/portal/processo/verProcessoAndamento.asp?incidente=4803092 consultado em 20.12.2017.

42 Decisão da $3^{\text {a }}$ Turma do TST, no Recurso de Revista no.1355-21.2015.5.12. 0047, cujo relator é o Dr. Relator: Ministro Mauricio Godinho Delgado com decisão publicada 10.11.2017.

${ }^{43}$ SILVA, Thiago de Carvalho e Silva e. O direito à felicidade e o dano moral existencial. Jornal Valor Econômico. Disponível em: http://www.valor.com.br/legislacao/3522078/o-direito-felicidade-e-o-dano-moralexistencial. Acesso em 19.12.2017

44SANSEVERINO, Paulo de Tarso Vieira. Princípio da reparação integral. São Paulo: Saraiva, 2011, p. 303-305. 
apresenta o dano moral em duas subdivisões: "dano ao projeto de vida" e de "dano à vida de relação". Para o autor, o primeiro refere-se ao dano existencial, onde a vítima tem suas expectativas futuras frustradas em relação ao futuro, seja no campo profissional (como algum incidente que cause lesão permanente no corpo da vítima, por exemplo, a perda dos dedos das mãos de um pianista ou de um cirurgião, ou a perda das pernas de um jogador de futebol) seja no campo privado (como um acidente de trânsito que lesiona, permanentemente, uma pessoa impossibilitando-a de gerar filhos biológicos).

A segunda subdivisão trata da impossibilidade de manter atividades habituais, fato comum em vítimas de abuso sexual, onde o dano se estende no tempo, impedindo de se relacionarem sexualmente com outra pessoa.

Assim, o "dano ao projeto de vida", "dano à vida de relação", "dano existencial" ou “dano à busca pela felicidade" configuram-se espécies autônomas de danos morais, pois fazem parte da esfera subjetiva do indivíduo e são indenizáveis pelas consequências advindas, onde a vítima foi restringida de consumar suas escolhas pessoais e limitando suas possibilidades de encontrar a felicidade. Salienta-se, aqui, que a reparação cabe diante da restrição de opções impostas à vítima e não na desilusão em si.

\subsection{DANO COLETIVO}

Danos morais coletivos são os decorrentes de ofensa a direitos da personalidade, que atingem, ao mesmo tempo, pessoas determinadas ou determináveis, cuja reparação tem fundamento no artigo $6^{\circ}$, VI, do Código de Defesa do Consumidor.

Tartuce lembra o Informativo 418, do Superior Tribunal de Justiça, no qual há duas publicações distintas acerca do reconhecimento do dano moral coletivo reparável e que traduzem, ao menos até o ano da publicação de sua obra, a divergência de entendimentos entre a $1^{\mathrm{a}}$ e a $2^{\mathrm{a}}$ Turmas daquela Corte 45 . Contudo, o Código de Defesa do Consumidor, em seus artigos $6^{\circ}$, VI, e 83, e a Lei de Ação Civil Pública, em seu artigo $1^{\circ}$, preveem expressamente a reparação de danos coletivos $^{46}$.

45 TARTUCE, Flávio. Op. cit. ,p. 455.

46 SCHREIBER, Anderson. Op.cit. p. 89-90. 
Vale a pena citar interessante julgado, proferido pela $4^{\mathrm{a}}$ Turma do Superior Tribunal de Justiça, no qual se reconheceu, em tese, a existência de dano moral coletivo como uma espécie autônoma de dano, embora não se tenha configurado na hipótese daqueles autos:

\begin{abstract}
Não cabe condenação a reparar dano moral coletivo quando, de cláusula de contrato de plano de saúde que excluiu a cobertura de próteses cardíacas indispensáveis a procedimentos cirúrgicos cobertos pelo plano, não tenham decorrido outros prejuízos além daqueles experimentados por quem, concretamente, teve o tratamento embaraçado ou teve de desembolsar os valores ilicitamente sonegados pelo plano. Como categoria autônoma de dano, a qual não se relaciona necessariamente com os tradicionais atributos da pessoa humana relativos à dor, sofrimento ou abalo psíquico, é possível afirmar-se cabível o dano moral coletivo. Além disso, embora o mesmo direito não pertença, a um só tempo, a mais de uma categoria de direito coletivo (direitos difusos, coletivos em sentido estrito e individuais homogêneos), isso não implica dizer que, no mesmo cenário fático ou jurídico conflituoso, violações simultâneas de direitos de mais de uma espécie não possam ocorrer. No entanto, na hipótese não se vislumbra dano de ordem coletiva, cujas vítimas seriam os atuais contratantes do plano de saúde, nem de ordem difusa, cujas vítimas seriam os indetermináveis futuros contratantes do plano. Os prejuízos, na hipótese, dizem respeito a direitos individuais homogêneos. Na verdade, a cláusula contratual restritiva permanece inoperante até que algum contratante venha a pleitear o serviço por ela excluído. Antes disso, é mera previsão contratual abstrata, incapaz de gerar qualquer efeito fora da idealização normativa avençada. Aplica-se a antiga - e cotidianamente repetida - ideia segundo a qual a responsabilidade civil requer, de regra, ilegalidade da conduta (salvo exceções de responsabilização por ato lícito), dano e nexo causal. Se é certo que a cláusula contratual em apreço constitui reconhecida ilegalidade, não é menos certo que nem toda ilegalidade se mostra apta a gerar dano, circunstância essa que se faz presente no caso em exame. 47
\end{abstract}

\title{
5.6 DANO SOCIAL
}

Danos sociais são aqueles que afetam toda sociedade e se relacionam com o princípio adotado pelo Código Civil de 2002, que valorizou o coletivo, o social, em detrimento da proteção individual ${ }^{48}$, cuja violação pode ser reparada com fundamento no artigo $6^{\circ}$, VI, do Código de Defesa do Consumidor.

Miragem entende que o dano social é uma variante do dano coletivo e que pode afetar gerações presentes e futuras. Contudo, o autor afirma que há controvérsia acerca da aceitação de dano social à gerações futuras, em face da eventual falta de certeza do dano, um de seus

\footnotetext{
47 Informativo 0547 de 08.10.2014 - 4a Turma -REsp 1.293.606-MG, Rel. Min. Luis Felipe Salomão, julgado em 02.09.2014. Disponível em: www.stj.gov.br. Acesso em: 21.06.2017.
}

48 TARTUCE, Flávio. Op. cit., p. 457. 
critérios $^{49}$. Já para Tartuce, os danos sociais podem gerar repercussões materiais ou morais e, portanto, distinguem-se dos danos coletivos, que são apenas extrapatrimoniais 50 .

O maior ganho ao se reconhecer o dano social é o caráter punitivo da indenização, o que tende a evitar novos comportamentos indesejados, do ponto de vista da convivência coletiva e da paz social, objetivo precípuo do direito. Neste sentido, busca-se punir o comportamento socialmente reprovável51.

Ainda, pode-se argumentar problemas relacionados à legitimidade ou à destinação do produto da indenização em caso de reconhecimento do dano social. Quanto à legitimidade, a questão fica superada com a Lei no 7.347/85, sendo os mesmos legitimados para a defesa de direitos difusos em juízo. Nesse sentido, cite-se decisão que reconheceu a existência de dano social indenizável, pela prática de ato ilícito perpetrado contra adolescente, em unidade de internação, por meio de ação civil pública proposta pelo Ministério Público ${ }^{52}$.

A destinação da indenização merece o tópico distinto, com proposta legislativa, abordada neste artigo.

\subsection{DESTINAÇÃO DO PRODUTO DA INDENIZAÇÃO POR DANO COLETIVO E DO DANO SOCIAL:} PROPOSTA LEGISLATIVA

\footnotetext{
${ }^{49}$ MIRAGEM, Bruno.Op.Cit,.p. 217-218.

50 TARTUCE, Flávio. Op. cit., p. 457.

51 'É nula, por configurar julgamento extra petita, a decisão que condena a parte ré, de ofício, em ação individual, ao pagamento de indenização a título de danos sociais em favor de terceiro estranho à lide. Inicialmente, cumpre registrar que o dano social vem sendo reconhecido pela doutrina como uma nova espécie de dano reparável, decorrente de comportamentos socialmente reprováveis, pois diminuem o nível social de tranquilidade, tendo como fundamento legal o art. 944 do CC. Desse modo, diante da ocorrência de ato ilícito, a doutrina moderna tem admitido a possibilidade de condenação ao pagamento de indenização por dano social, como categoria inerente ao instituto da responsabilidade civil, além dos danos materiais, morais e estéticos. Registre-se, ainda, que na V Jornada de Direito Civil do CJF foi aprovado o Enunciado 455, reconhecendo a existência do denominado dano social: 'A expressão dano no art. 944 abrange não só os danos individuais, materiais ou imateriais, mas também os danos sociais, difusos, coletivos e individuais homogêneos a serem reclamados pelos legitimados para propor ações coletivas (...)"'(Rcl 12.062-GO, Rel. Min. Raul Araújo, julgado em 12.11.2014. Informativo 0552 de 17.12.2014).

52 “O Ministério Público tem legitimidade para promover ação civil pública a fim de obter compensação por dano moral difuso decorrente da submissão de adolescentes a tratamento desumano e vexatório levado a efeito durante rebeliões ocorridas em unidade de internação. Isso porque, segundo o art. 201, V, do ECA, o MP é parte legítima para 'promover o inquérito civil e a ação civil pública para a proteção dos interesses individuais, difusos ou coletivos relativos à infância e à adolescência'. Precedente citado: REsp 440.502-SP, Segunda Turma, DJe 24/9/2010" (AgRg no REsp 1.368.769-SP, Rel. Min. Humberto Martins, julgado em 06.08.2013. Informativo 0526).
} 
O artigo 13 da Lei no 7.347/85 prevê o fundo de interesses difusos, que tinha por objetivo, quando de sua criação, reconstituir os bens lesados. Posteriormente, a destinação dos recursos dos fundos foi sendo ampliada.

O artigo $1^{\text {o }}$ da Lei $n^{\circ} 9.008 / 95$ prevê destinação específica dos fundos, tais como recuperação de bens lesados, promoção de eventos educativos ou científicos, edição de material informativo, modernização de órgãos públicos, responsáveis pela execução de políticas relativas às áreas de interesses objetivados na Lei de Ação Civil Pública, entre outras destinações. O produto do fundo não pode ser utilizado para pagamento de perícias, por expressa proibição legal ${ }^{53}$.

Contudo, em ações coletivas, de iniciativa do Ministério Público, questiona-se quem irá custear a perícia a ser produzida nos autos: se o Estado ou algum órgão público, tal como a Fazenda Pública, já que o dinheiro do fundo não pode ser utilizado para tal finalidade. Surge, desta forma, a necessidade de ampliar as finalidades de utilização dos recursos, provenientes do fundo de direitos difusos, em parte para custear perícias em processos coletivos, o que deve ser feito por meio legislativo:

Diante das dificuldades na realização de perícias, tanto nos inquéritos civis como nas ações civis públicas, existe uma aspiração dos membros do Ministério Público no sentido de terem acesso às verbas do fundo para custear suas investigações. Entretanto, se, de lege ferenda, tal solução pode ser cogitada, hoje, porém, lege lata, é inviável. Com efeito, sob o sistema vigente, tanto a lei federal que dispõe sobre o fundo nacional para reparação de interesses difusos, como a lei estadual paulista que dispõe sobre o fundo estadual respectivo - ambas não prevêem a possibilidade de usar os recursos do fundo em perícias, vistorias ou despesas processuais para condenação das ações civis públicas ou coletivas. No direito vigente, pois, não se pode usar o produto do fundo em contrariedade com sua destinação legal, como para custear perícias ${ }^{54}$

Ora, a discussão sobre quem deve custear a produção da prova, na melhor das hipóteses, atrasa o processo coletivo, isso quando não representa um óbice à perquirição do próprio direito; de um ou outro modo estamos diante de impedimento à Justiça. Ao trazer a questão para a hipótese deste trabalho, constatamos que a dificuldade na produção da prova do dano social ou coletivo pode impactar na efetivação deste direito em si.

Pondera-se, portanto, a necessidade de mudança legislativa para autorizar a utilização do dinheiro do fundo de direitos difusos para custeio de prova pericial, o que pode garantir a efetivação do direito à reparação de danos sociais e coletivos acima discutidos.

53 MAZZILLI, Hugo Nigro. A defesa dos interesses difusos em juízo. São Paulo: Saraiva, 2015.p. 606-608. 54 Ibid, p. 532. 


\section{CONCLUSÃO}

O princípio constitucional da dignidade da pessoa humana, como fundamento da República, colocou a pessoa no centro da proteção do direito, construindo um direito mais humanizado, existencial.

É possível notar em julgados, a preocupação em valorizar a função compensatória do dano e o aumento quantitativo de novas espécies de danos.

Em pesquisa jurisprudencial e doutrinária, podemos citar, entre novas categorias, dano por abandono afetivo, dano estético, dano por perda da chance, dano ao projeto de vida, dano à vida de relação, dano coletivo, dano social que, entre outros tantos, configuram danos autônomos, decorrentes da lesão a atributos da personalidade humana, sem prejuízo de outros que não mencionados neste trabalho.

O problema acerca da existência de novas espécies de danos, ou novas denominações do mesmo dano moral, pode ser resolvido ao entendermos que estes "novos danos" são autônomos, decorrem da necessidade de se atribuir integral reparação e encontram fundamento no princípio da dignidade da pessoa humana, conteúdo preenchido por vários atributos da personalidade humana.

Cumpre igualmente observar que, cada dano destas "novas espécies" deve corresponder a um pedido separado nas ações judiciais, que buscam sua reparação. $\mathrm{O}$ conhecimento de um em detrimento de outro, quando pedidos conjuntamente, impactam na sucumbência.

Por último, pode-se concluir que as novas tecnologias e formas de vida, em uma sociedade cada vez mais plural, podem ensejar outras espécies de danos, ao lado das que foram expostas neste artigo, sempre na principal função constitucional: garantir dignidade à pessoa humana.

\section{REFERÊNCIAS BIBLIOGRÁFICAS}


DELGADO, Mario Luiz. O direito fundamental à busca da felicidade: reflexões sobre um novo dano. Disponível em: http://www.mldadv.com.br/cat-artigos/119-o-direito-fundamental$\% \mathrm{C} 3 \% \mathrm{~A} 0$-busca-da-felicidade-reflex $\% \mathrm{C} 3 \% \mathrm{~B} 5$ es-sobre-um-novo-dano.html. Acesso em: 19.12.2017.

DIAS, Maria Berenice. Manual de direito das famílias. $7^{0}$ ed. São Paulo: Revista dos Tribunais, 2010.

HIRONAKA, Giselda Maria Fernandes de Novaes. Os contornos jurídicos da responsabilidade afetiva nas relações entre pais e filhos - além da obrigação legal de caráter material. 2005. Disponível em: www.egov.ufsc.br/portal/sites/default/files/anexos/ 32839-40754-1 PB.pdf. Acesso em 15 jun. 2017.

LOPEZ, Teresa Ancona. O dano estético. São Paulo: Revista dos Tribunais, 2004.

MAZZILLI, Hugo Nigro. A defesa dos interesses difusos em juízo. $28^{\circ}$ ed. São Paulo: Saraiva, 2015.

MIRAGEM, Bruno. Direito civil: responsabilidade civil. São Paulo:Saraiva, 2015.

SANSEVERINO, Paulo de Tarso Vieira. Princípio da reparação integral. São Paulo: Saraiva, 2011.

SCHREIBER, Anderson. Direitos da personalidade. $3^{\circ}$ ed.São Paulo: Atlas, 2014.

- Novos paradigmas da responsabilidade civil: da erosão dos filtros da reparação à diluição dos danos. $6^{\circ}$ ed.São Paulo: Atlas, 2015.

SILVA, Thiago de Carvalho e Silva e. O direito à felicidade e o dano moral existencial. Jornal

Valor Econômico. Disponível no site: www.valor.com.br/legislacao/3522078/o-direitofelicidade-e-o-dano-moral-existencial .Acesso em 19.12.2017.

TARTUCE, Flávio. Direito civil: direito das obrigações e responsabilidade civil. $11^{\circ}$ ed.São Paulo: Método, 2016.

. 2016: o ano da afetividade na jurisprudência superior brasileira. Disponível em: www.flaviotartuce.adv.br. Acesso em: 15 jun. 2017.

Direito civil 1: Lei de Introdução e parte geral. São Paulo: Método, 2015.

VENOSA, Sílvio de Salvo. Direito civil: parte geral. $8^{\circ}$ ed.São Paulo: Atlas, 2008.

Direito civil: responsabilidade civil. $8^{\circ}$ ed.São Paulo: Atlas, 2008. 
ZALCMAN, Vivian Gerstler. O direito à busca pela felicidade por intermédio da mediação na dissolução do casamento e da união estável. Monografia (Mestrado), Curso de Direito, PUC/SP, 2017.

Sites consultados

Superior Tribunal de Justiça: www.stj.jus.br

Supremo Tribunal Federal: www.stf.jus.br

Tribunal Superior do Trabalho: $\underline{\text { www.tst.jus.br }}$ 